\title{
O PROGRAMA RESIDÊNCIA PEDAGÓGICA DA UFT/ARRAIAS E OS DESAFIOS DAS ESCOLAS DO CAMPO
}

The UFT / Arraias Pedagogical residence Program and the challenges of camp schools

El Programa de Residencia Pedagógica de UFT / Arraias y los desafíos de las escuelas del campo

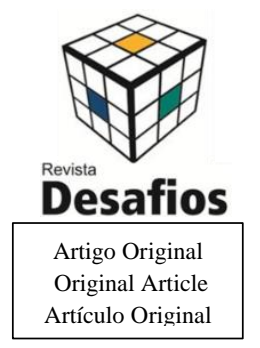

Aparecida de Jesus Soares Pereira" ${ }^{* 1}$, Waldir Pereira da Silva ${ }^{1}$, Mirian Ferreira da Cunha ${ }^{1}$, Viviane Fernandes da Conceição ${ }^{1}$

${ }^{1}$ Laboratório de Educação Musical, Curso de Licenciatura em Educação do Campo, Universidade Federal do Tocantins-UFT, Arraias -TO, Brasil.

*Correspondência: Curso de Licenciatura em Educação do Campo, Universidade Federal do Tocantins - UFT, Av. Juraíldes de Sena e Abreu, Setor Buritizinho/ sala 10 - Bloco Bala, Arraias - Tocantins, Brasil. CEP:77.330-000. e-mail: cida.soares@uft.edu.

Artigo recebido em 03/04/2020 aprovado em 09/04/2020 publicado em 17/04/2020.

\section{INTRODUÇÃO}

Durante a residência pedagógica, as experiências foram momentos de extrema relação com a realidade educacional, onde se experimentou vivências e práticas do ensino, podendo se destacar algumas considerações relevantes, a saber: a) o planejamento que foi essencial; b) a organização e prévia das atividades, observação e prática de estágios, palestras, oficinas, são atitudes como práticas obrigatórias; c) Conhecer o público, o espaço e sua contextualidade, ajudou na consolidação de uma prática educativa mais sólida, d) Não bastou ensinar foi preciso compreender o outro, suas limitações, anseios, sonhos e projetos, sem a coletividade, a educação não se destaca sem causas reais, transformações positivas, e) O diálogo entre teoria e prática, porém nem toda teoria se encaixou na prática e nem toda prática serviu para outras realidades; f) No trato da mediação pedagógica, no desenvolvimento de atividades com alunos, foi preciso destacar que; existem diferenças, que foram tratadas de forma ética, democrática e dialógica, para o bem de todos, do respeito, da valorização do outro, etc. g) identidade DOI: http://dx.doi.org/10.20873/uftsupl2020-8822 cultural, relações sociais, sustentabilidade foram pontos chaves no processo pensando-se sempre nos atores do processo e no contexto campesino.

Segundo destaca a CAPES, "O Programa de Residência Pedagógica é uma das ações que integram a Política Nacional de Formação de Professores. Desse modo, tem como objetivo induzir o aperfeiçoamento da formação prática nos cursos de licenciatura, promovendo a imersão do licenciando na escola de educação básica, a partir da segunda metade de seu curso". (CAPES 2020). Ainda segundo a CAPES, o programa articulada aos demais programas da Capes que compõem a Política Nacional. Diante desta perspectiva, tem como "premissas básicas o entendimento de que a formação de professores nos cursos de licenciatura deve assegurar aos seus egressos, habilidades e competências que lhes permitam realizar um ensino de qualidade nas escolas de educação básica". (CAPES, 2020). 


\section{METODOLOGIAS E MATERIAIS}

O período do residência pedagógica é na verdade uma reorganização do pensar, e das reflexões adquiridas ao longo do Curso de Licenciatura em Educação do Campo - Códigos e Linguagens Artes Visuais e Música da Universidade Federal do Tocantins- Campus de Arraias, em relação à prática educativa em sala de aula.

Desse modo, pensar, refletir e agir, exige planejamento eficaz, que para mediar à prática de aprendizagens em uma instituição necessita de alguns trâmites legais, como por exemplo: agendamento de visitas e reconhecimento do espaço campo de observação, pesquisa e ação educacional, conhecer a clientela, os problemas, o Currículo Referencial, os Projetos de Ensino, o Projeto Político Pedagógico, etc.

Depois desses trâmites legais e exigidos pela Universidade e a Coordenação do curso e professores, diagnosticado um tema e ou problema, o planejamento da prática educativa é essencial para organizar as ideias e desenvolver o trabalho com alunos. Importante ressaltar que toda ação gera reação, o que exige de cada residente, maior responsabilidade para que sua prática tenha resultados positivos, não somente pelos aspectos quantitativos da avaliação para fins de notas para o discente em formação, mas para consolidar sua carreira profissional como futuro educador.

Alguns materiais foram essenciais para a realização das atividades, como pinturas. Foram utilizadas tintas produzidas com produtos naturais e outros como açafrão, cola, água, café, terra, papel, pincel, esponjas, etc. Na música foram trabalhadas as melodias destacando os gostos musicais, as letras, a mensagem explicita em cada música. Por isso, observa, no entanto, que a educação do campo é, portanto uma modalidade de ensino que requer um olhar diferenciado, de forma que este espaço social, dinâmico, cultural e produtivo, tenha sua identidade respeitada, suas demandas atendidas, suas possibilidades de progresso e evolução tenham incentivos claros e sólidos na educação, conforme destaca o Art. 28 da Lei de Diretrizes e Bases da Educação Nacional,

na oferta de educação básica para a população rural, os sistemas de ensino promoverão as adaptações necessárias à sua adequação, às peculiaridades da vida rural e de cada região, especialmente: I - conteúdos curriculares e metodologias apropriadas às reais necessidades e interesses dos alunos da zona rural; II - organização escolar própria, incluindo adequação do calendário escolar às fases do ciclo agrícola e às condições climáticas; III - adequação à natureza do trabalho na zona rural. (BRASIL, 1996).

O campo também é lugar de trabalho, de tecnologias, de diversas relações que devem ser vistas do ponto de vista educacional, como afirma Lopes e Ferreira (2004), a saber;

Cabe à educação preparar quadros, criar mecanismos, definir e aplicar estratégias para a consecução de medidas que garantam a preparação e a consolidação dos fundamentos do trabalho e das tecnologias produtivas na direção dos horizontes apontados e demandados pelo próprio movimento social do campo. (LOPES e FERREIRA 2004, p. 14),

Através dos diferentes estudos, pesquisas, seminários, participações em debates, conferências e outras experiências ao longo do curso, pôde-se destacar alguns pontos para pensar a educação do campo e considerar aspectos que levem em consideração os sujeitos camponeses, cidadania, cultura, relações sociais, economia e construção de currículo com identidade camponesa, a formação do educador, e a capacidade de observar e dominar as especificidades que envolvem as diferentes relações camponesas nos diversos contextos.

Diante dos pontos levantados, observa-se nas palavras de Lacki (2005), que educação sendo ela do campo ou não, perpassam simples fato de alfabetizar e Revista Desafios - v. 7, n. Supl. RP-UFT, 2020 
ensinar conteúdos previamente estabelecidos pelos sistemas de ensino e seus currículos, assim diz:

A escola, além de alfabetizar e transmitir conhecimentos gerais, deve possibilitar ao educando a compreensão do meio em que vive, capacitando-o para descobrir formas apropriadas para conviver com a seca. As escolas devem adotar uma pedagogia popular e currículos em consonância com a realidade do semi-árido com ênfase para o resgate e valorização da sabedoria popular. (LACKI 2005, p. 4).

Não se faz educação do campo com o mesmo pensar de um ensino para o meio urbano. São culturas, modos de vida, experiências, saberes e fazeres diferentes, que podem dialogar entre si, mas que no trato das relações de aprendizagens são contextos e realidades diferentes. Importante ressaltar que a educação do campo que não considera o sentimento de pertencimento dos sujeitos camponeses que nele vivem, de nada surtirá efeitos transformadores positivos.

\section{RESULTADOS E DISCUSSÃO}

O educador deve propiciar no âmbito de sua prática pedagógica ferramentas, conteúdos, metodologias, estratégias de ensino, atividades que dialogam com a realidade, que promova uma educação significativa para o homem do campo.

Sem uma prática de ensino significativa, que desperte no homem do campo o sentimento de pertencimento, de evolução, progresso e sustentabilidade em seu espaço de vivências, experiências e sustento, a educação não terá nem um sentido e/ou valor.

\section{CONCLUSÃO}

É na perspectiva de uma educação libertadora, dialógica e contextual, ou seja, pensada, organizada e mediada no e para o homem do campo, que se alcançará a transformação positiva esperada.

\section{AGRADECIMENTOS}

Os agradecimentos especiais são dedicados à CAPES - Coordenação de Aperfeiçoamento de Pessoal de Nível Superior. À Universidade Federal do Tocantins - Campus de Arraias - TO. Ao Curso de Licenciatura em Educação do Campo - Artes Visuais e Música - Campus Arraias. À equipe gestora, professores e alunos do Colégio Estadual Irany Nunes do Prado no Distrito Prata - Município de Monte Alegre de Goiás.

Todos os autores declararam não haver qualquer potencial conflito de interesses referente a este artigo.

\section{REFERÊNCIAS}

BRASIL, Lei de Diretrizes e Bases da Educação Nacional - LDBEN - LEI N 9.394 de 20 de dezembro de 1996 - Brasília DF, 1996.

COORDENAÇÃO DE APERFEIÇOAMENTO DE PESSOAL DE NÍVEL SUPERIOR - CAPES. Programa de Residência Pedagógica. Disponível em: https://www.capes.gov.br/educacaobasica/programa-residencia-pedagogica. Acesso em 2 de janeiro de 2020.

\section{LACKI, Polan. Educação rural: para que? E para} quem? [S.n.: s.n., Rondônia 2005].

Se a Educação rural fizesse os "deveres de casa..." os problemas da agricultura estariam solucionados. EDITORA UNIVERSIDADE FEDERAL DE RONDÔNIA, 2005. Disponível em http://www.primeiraversao.unir.br/artigos_volumes/1 89_.pdf, acesso 02 de janeiro de 2020.

LOPES, Na. a Maria; FERREIRA, Eudson de Castro. Tybisirá: educação do campo e visibilidade social. Brasília: Idéa, 2004. 